Supporting Information for

\title{
Nanowire Lasers of Formamidinium Lead Halide Perovskites and Their Stabilized Alloys with Improved Stability
}

Yongping $\mathrm{Fu}^{1 \dagger}$, Haiming Zhu ${ }^{2 \dagger}$, Alex W. Schrader ${ }^{1}$, Dong Liang ${ }^{1}$, Qi Ding ${ }^{1}$, Prakriti Joshi ${ }^{2}$, Leekyoung Hwang ${ }^{1}, X-Y . Z h u^{2} *$ and Song $\operatorname{Jin}^{1} *$

${ }^{1}$ Department of Chemistry, University of Wisconsin-Madison, 1101 University Avenue, Madison, Wisconsin 53706, United States

${ }^{2}$ Department of Chemistry, Columbia University, New York, New York 10027, USA

†These authors contributed equally to this work.

*E-mail: xyzhu@columbia.edu or jin@chem.wisc.edu 


\section{Materials Synthesis and Characterizations}

All chemicals and regents were purchased from Sigma-Aldrich and used as received unless noted otherwise.

Synthesis of $\mathbf{C H}\left(\mathbf{N H}_{2}\right)_{2} \mathbf{X}(\mathbf{F A X}, \mathbf{X}=\mathbf{I}, \mathbf{B r})$. The synthesis of formamidinium halide, $\mathrm{CH}\left(\mathrm{NH}_{2}\right)_{2} \mathrm{X}$ (FAX, X=I, Br), followed the previous literature. ${ }^{\mathrm{S} 1}$ Specifically, the $\mathrm{CH}\left(\mathrm{NH}_{2}\right)_{2} \mathrm{I}$ or $\mathrm{CH}\left(\mathrm{NH}_{2}\right)_{2} \mathrm{Br}$ was synthesized by slowly dissolving formamidinium acetate powder and HI ( $57 \mathrm{wt} \%$ in water) or $\mathrm{HBr}$ (48 wt\% in water) in a evaporating dish in a molar ratio of 1:2. The $\mathrm{CH}\left(\mathrm{NH}_{2}\right)_{2} \mathrm{I}$ or $\mathrm{CH}\left(\mathrm{NH}_{2}\right)_{2} \mathrm{Br}$ salt gradually precipitated as the solvent was carefully removed at $100{ }^{\circ} \mathrm{C}$ on a hot plate. The product was collected by filtration and washed with diethyl ether several times. Finally, the product was recrystallized in ethanol to form white crystals, and dried at $50{ }^{\circ} \mathrm{C}$ in an oven for 24 hours.

Growth of hexagonal phase $\mathrm{CH}\left(\mathrm{NH}_{2}\right)_{2} \mathrm{PbI}_{3}\left(\mathrm{FAPbI}_{3}\right)$ nanowires and the conversion to the perovskite phase. The single-crystal hexagonal (yellow) phase $\mathrm{CH}\left(\mathrm{NH}_{2}\right)_{2} \mathrm{PbI}_{3}$ nanowires were synthesized by immersing a piece of $\mathrm{PbAc}_{2}$ coated glass slide in a $20 \mathrm{mg} / \mathrm{mL} \mathrm{CH}\left(\mathrm{NH}_{2}\right)_{2} \mathrm{I}$ solution in isopropanol (IPA) in an oven at $50{ }^{\circ} \mathrm{C}$, with the $\mathrm{PbAc}_{2}$ coated side facing down. The $\mathrm{PbAc}_{2}$ thin film was prepared by dropcasting $100 \mathrm{mg} / \mathrm{mL} \mathrm{PbAc}_{2} \cdot 3 \mathrm{H}_{2} \mathrm{O}$ aqueous solution on a glass slide and dried at $60{ }^{\circ} \mathrm{C}$. We should note that we keep spreading out the lead acetate solution to obtain a uniform film on the substrate during the drying process, since the solution tended to shrink on the substrate. Upon dipping the chip into the $\mathrm{CH}\left(\mathrm{NH}_{2}\right)_{2} \mathrm{I}$ solution, the film turned yellow. After a reaction time of $\sim 20 \mathrm{~h}$, the glass slide was taken out, and subsequently washed in isopropanol and dried under $\mathrm{N}_{2}$ flow. The perovskite (black) phase $\mathrm{CH}\left(\mathrm{NH}_{2}\right)_{2} \mathrm{PbI}_{3}$ nanowires were obtained by annealing the chip on a hot plate at $170{ }^{\circ} \mathrm{C}$ for $5 \mathrm{~min}$, which resulted in the products to turn into black color.

Growth of single-crystal $\mathrm{NWs}$ of $\mathrm{CH}_{3} \mathrm{NH}_{3} \mathrm{Br}$ (MABr) stabilized $\mathrm{CH}\left(\mathrm{NH}_{2}\right)_{2} \mathrm{PbI}_{3} \mathrm{NW}$ (FA0.75MA0.25) Pb(I2.7Br0.3), $\mathrm{CH}\left(\mathrm{NH}_{2}\right)_{2} \mathrm{PbBr}_{3}$, and other (FA1-zMAz)Pb(Br3-y $\left.\mathrm{I}_{\mathrm{y}}\right)$ alloy. To synthesize single crystal $\left(\mathrm{FA}_{0.75} \mathrm{MA}_{0.25}\right) \mathrm{Pb}\left(\mathrm{I}_{2.7} \mathrm{Br}_{0.3}\right) \mathrm{NWs}$, a $\mathrm{PbAc}_{2}$ film on glass slide was first dipped into $1 \mathrm{~mL} 40 \mathrm{mg} / \mathrm{mL}$ MAI/IPA solution for $\sim 2 \mathrm{~min}$ to form a "seeding layer" on the substrate surface. The substrate was then placed into $1 \mathrm{~mL}$ of mixed IPA solution of FAI with a concentration of $20 \mathrm{mg} / \mathrm{mL}$ and $\mathrm{MABr}$ with a concentration of $5 \mathrm{mg} / \mathrm{mL}$ at room temperature for 
$\sim 15 \mathrm{~h}$, with the $\mathrm{PbAc}_{2}$ coated side facing up (facing down works too). It is worth noting thatincreased reaction time may lead to the growth of hexagonal phase NWs. For the synthesis of $\mathrm{FAPbBr}_{3} \mathrm{NWs}$, the $\mathrm{PbAc}_{2}$ film was immersed into $1 \mathrm{~mL}$ of $10 \mathrm{mg} / \mathrm{mL}$ FABr/IPA solution in an oven at $50{ }^{\circ} \mathrm{C}$ or at room temperature for $\sim 20 \mathrm{~h}$, with the $\mathrm{PbAc}_{2}$ coated side facing down. For the synthesis of $\left(\mathrm{FA}_{1-\mathrm{z}} \mathrm{MA}_{\mathrm{z}}\right) \mathrm{Pb}\left(\mathrm{Br}_{3-\mathrm{y}} \mathrm{I}_{\mathrm{y}}\right) \mathrm{NWs}$, the $\mathrm{PbAc}_{2}$ film was immersed into $1 \mathrm{~mL}$ of mixed IPA solution of $\mathrm{FABr}$ with a fixed concentration of $7 \mathrm{mg} / \mathrm{mL}$ and MAI with a series of concentrations ratio of $1,2,3,4$ and $5 \mathrm{mg} / \mathrm{mL}$, in an oven at $50{ }^{\circ} \mathrm{C}$ for $\sim 20 \mathrm{~h}$, with the $\mathrm{PbAc}_{2}$ coated side facing down.

Thermal gravimetric analysis (TGA). The $\mathrm{MAPbI}_{3}$ or $\mathrm{FAPbI}_{3}$ samples for TGA were prepared through precipitation from $\mathrm{MAPbI}_{3}$ or $\mathrm{FAPbI}_{3}$ solution in dimethylformamide (DMF) by adding toluene as an antisolvent. Specifically, $200 \mathrm{mg}$ of $\mathrm{PbI}_{2}$ powder and $69 \mathrm{mg}$ of MAI or $75 \mathrm{mg}$ of FAI with a molar ratio of 1:1 were dissolved in $0.8 \mathrm{~mL}$ DMF to form a solution with a concentration of $\sim 340 \mathrm{mg} / \mathrm{mL}$. Upon adding $\sim 5 \mathrm{~mL}$ of toluene into the solution, the $\mathrm{MAPbI}_{3}$ or $\mathrm{FAPbI}_{3}$ powders were precipitated and then collected by centrifugation at 10k rpm for $1 \mathrm{~min}$. Finally, the $\mathrm{MAPbI}_{3}$ and $\mathrm{FAPbI}_{3}$ powders were dried at $100{ }^{\circ} \mathrm{C}$ and $170{ }^{\circ} \mathrm{C}$, respectively. Thermal gravimetric analyses of the as-prepared samples were performed using a TA Instruments Q500 Thermogravimetric Analyzer with a ramping rate of $2{ }^{\circ} \mathrm{C} \mathrm{min}{ }^{-1}$ from room temperature up to $\sim 350{ }^{\circ} \mathrm{C}$ under a nitrogen or oxygen environment with a flow rate of 50.0 $\mathrm{mL} / \mathrm{min}$.

H-NMR determination of the FA/MA ratio in the $\left(\mathrm{FA}_{1-z} \mathrm{MA}_{z}\right) \mathbf{P b}\left(\mathrm{Br}_{3-\mathrm{y}} \mathrm{I}_{\mathbf{y}}\right)$ alloys. The various perovskite alloys were prepared by adding $0.15 \mathrm{~mL}$ of $100 \mathrm{mg} / \mathrm{mL} \mathrm{PbAc}_{2} \cdot 3 \mathrm{H}_{2} \mathrm{O}$ aqueous solution into $15 \mathrm{~mL}$ of a mixed IPA solution of FABr and MAI with the desired concentration ratio. To ensure a complete conversion, the solution was placed in an ultrasonic bath for around 5 $\min$. The powders were collected by centrifugation at $10 \mathrm{k} \mathrm{rpm}$ for $1 \mathrm{~min}$ and then dried at $100{ }^{\circ} \mathrm{C}$ in the air. To carry out H-NMR, the as-prepared powders were first dispersed in methanol-d4 and the resulting suspension was further ultrasonicated to dissolve the perovskites as much as possible. Then a clear solution could be obtained by removing the undissolved powders through centrifugation and used for H-NMR measurement using a Bruker $400 \mathrm{MHz}$ NMR spectrometer. HNMR (400 MHz, methanol-d4) of FAI: $7.86 \delta$ (s, 1H). HNMR (400 MHz, methanol-d4) of MAI: $2.56 \delta(\mathrm{s}, 3 \mathrm{H})$. 
Structural characterizations. The optical images of $\mathrm{FA}(\mathrm{MA}) \mathrm{PbX}_{3}$ nanostructures were obtained on an Olympus BX51M optical microscope. The scanning electron microscopy (SEM) images were collected on a LEO SUPRA 55 VP field-emission scanning electron microscope operated at $3 \mathrm{kV}$. Energy-dispersive X-ray spectroscopy (EDX) was performed on single NWs transferred onto a $\mathrm{SiO}_{2} / \mathrm{Si}$ wafer using a LEO SUPRA $55 \mathrm{VP}$ field-emission SEM equipped with an EDS detector operating at $15.0 \mathrm{kV}$. The PXRD data were collected on as-grown samples on glass substrates using a Bruker D8 Advance Powder X-ray Diffractometer with $\mathrm{Cu}$ K $\alpha$ radiation.

Optical characterization. ${ }^{\mathrm{S} 2}$ The optically pumped lasing measurements were carried out on a home-build far field epifluorescence microscope setup (Olympus, IX73 inverted microscope). NWs on as-grown substrates were dry-transferred and dispersed onto a silicon substrate covered with a $300 \mathrm{~nm}$ silica layer; each sample was mounted in a $\mathrm{N}_{2}$ gas filled cell for optical measurements. The $402 \mathrm{~nm}$ excitation light was generated from the second harmonic of the fundamental output $(805 \mathrm{~nm}, 100 \mathrm{fs}, 250 \mathrm{kHz}$ ) from a regenerative amplifier (Coherent RegA amplifier seeded by Coherent Mira oscillator). The light was focused onto the sample surface by a 50X, NA=0.5 objective (Olympus LMPLFLN50X) and the pulse duration was broadened to $150 \mathrm{fs}$. We optimized the laser beam size using lens in front of microscope to give a beam waist of $34 \mu \mathrm{m}$ (FWHM) to ensure uniform illumination of each NW. The polarization of the excitation beam was not changed since the absorption anisotropy in these NWs was small $(<$ $10 \%$ ). The emission from each NW was collected by the same objective and focused into a spectrograph (Princeton Instruments, IsoPlane 160) with $1200 \mathrm{~g} / \mathrm{mm}$ grating and detected by a liquid-N 2 cooled CCD (PyLoN 400 and PyLon IR). The instrument spectral resolution (FWHM) was $~ 0.1 \mathrm{~nm}$. All measurements were carried out at room temperature. Time resolved photoluminescence (TRPL) decay kinetics was collected on single NWs using a TCSPC module (B\&H, SPC130) and a SPAD detector (IDQ, id100-50) with an instrument response function 100 ps (FWHM).

\section{Supporting Figures}



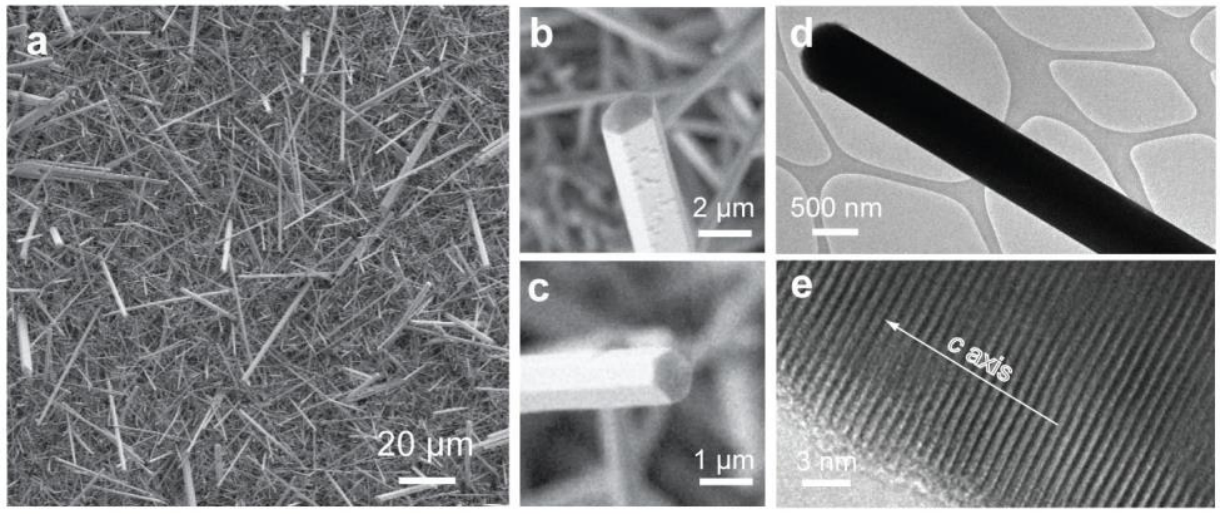

Figure S1. Structural characterization of the as-grown hexagonal phase $\mathrm{FAPbI}_{3} \mathrm{NWs}$. (a) SEM image of as-grown hexagonal phase $\mathrm{FAPbI}_{3} \mathrm{NWs}$ (b, c) Magnified SEM images of $\mathrm{FAPbI}_{3} \mathrm{NWs}$ showing hexagonal end facets. (d) Low-resolution TEM image of a hexagonal phase $\mathrm{FAPbI}_{3}$ NWs. (e) High-resolution TEM image of hexagonal phase $\mathrm{FAPbI}_{3} \mathrm{NWs}$ confirms the singlecrystal nature and the growth direction along the $c$ axis.
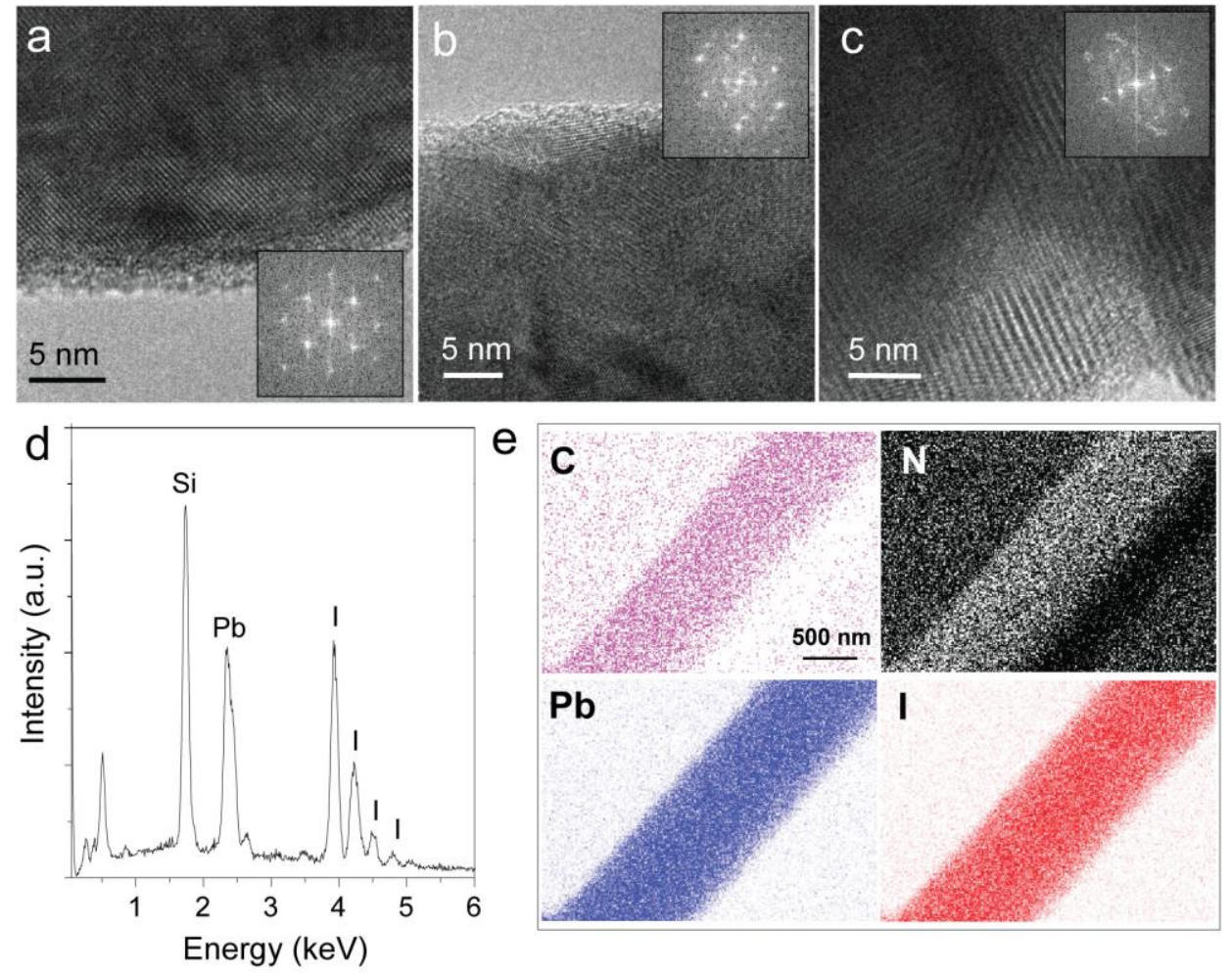

Figure S2. Structural characterization of the $\mathrm{FAPbI}_{3} \mathrm{NWs}$ after conversion. (a) High-resolution TEM image and the corresponding FFT pattern (inset) reveal the single crystallinity of a $\mathrm{FAPbI}_{3}$ NW after conversion. (b,c) High-resolution TEM images and the corresponding FFT patterns 
(inset) reveal the polycrystalline nature of $\mathrm{FAPbI}_{3} \mathrm{NWs}$ after conversion. (d) Energy dispersive $\mathrm{X}$-ray spectroscopy (EDS) of a typical converted $\mathrm{FAPbI}_{3} \mathrm{NW}$ on $\mathrm{SiO}_{2} / \mathrm{Si}$ substrate, and (e) the corresponding EDS mapping showing the uniform distribution of $\mathrm{C}, \mathrm{N}, \mathrm{Pb}$ and I elements.
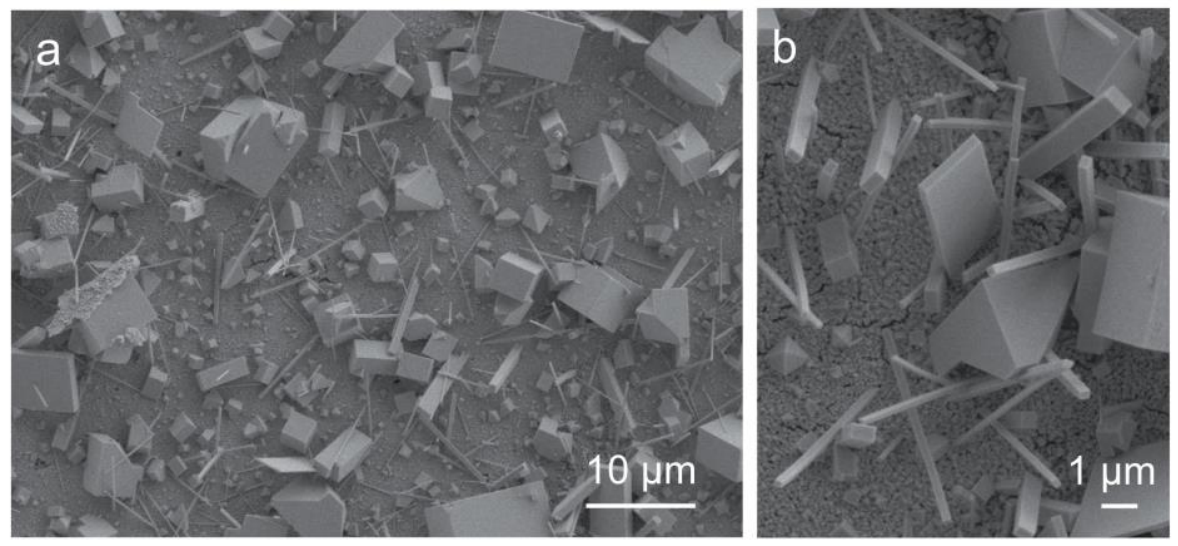

Figure S3. More SEM image of the MABr-stabilized $\mathrm{FAPbI}_{3} \mathrm{NWs}$, showing the length and width distribution
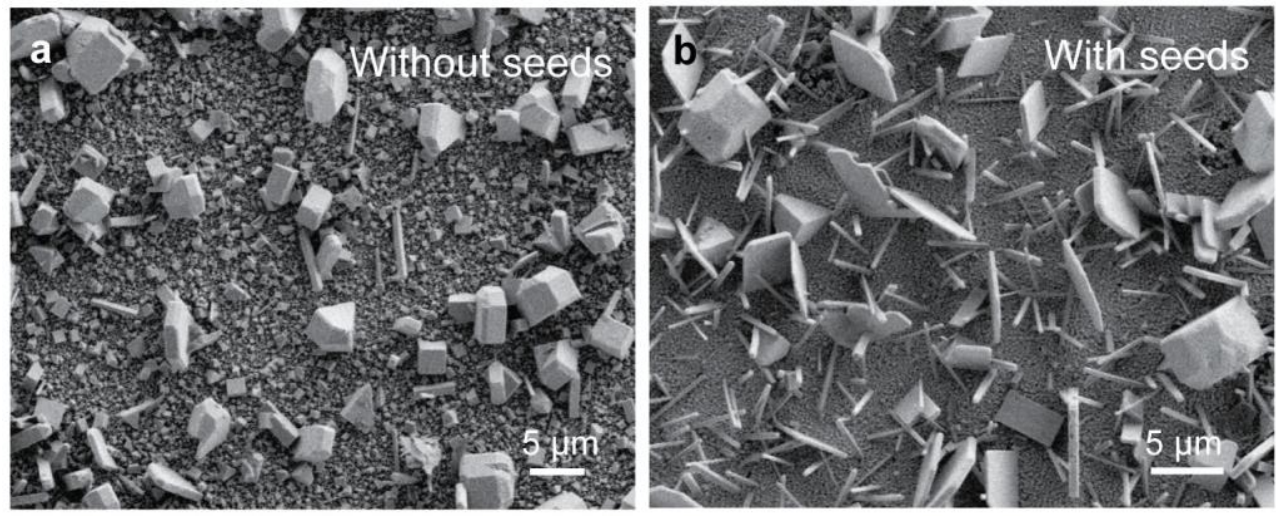

Figure S4. (a) SEM image of the MABr-stabilized $\mathrm{FAPbI}_{3} \mathrm{NWs}$ grown without the "seed layer". (b) SEM image of the MABr-stabilized $\mathrm{FAPbI}_{3} \mathrm{NWs}_{\text {grown }}$ with the "seed layer". The "seed layer" was formed by pre-dipping the $\mathrm{PbAc}_{2}$ film into $1 \mathrm{~mL} 40 \mathrm{mg} / \mathrm{mL}$ MAI/IPA solution for 2 $\min$. 


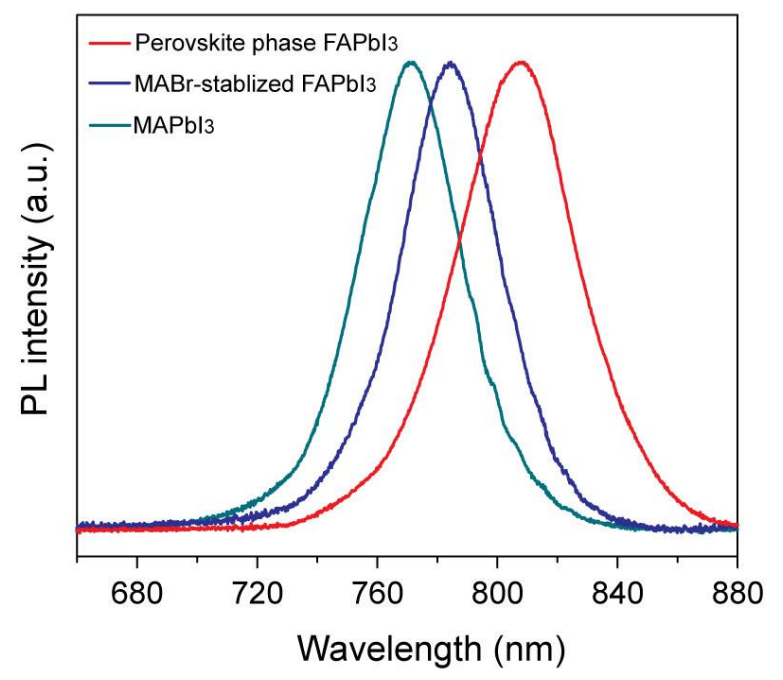

Figure S5. Confocal microscopy photoluminescence spectra of a single $\mathrm{MAPbI}_{3} \mathrm{NW}$ (green curve), $\mathrm{MABr}$-stabilized $\mathrm{FAPbI}_{3} \mathrm{NW}$ (blue curve), and perovskite phase $\mathrm{FAPbI}_{3} \mathrm{NW}$ (red curve) excited by a $532 \mathrm{~nm}$ laser source at room temperature.
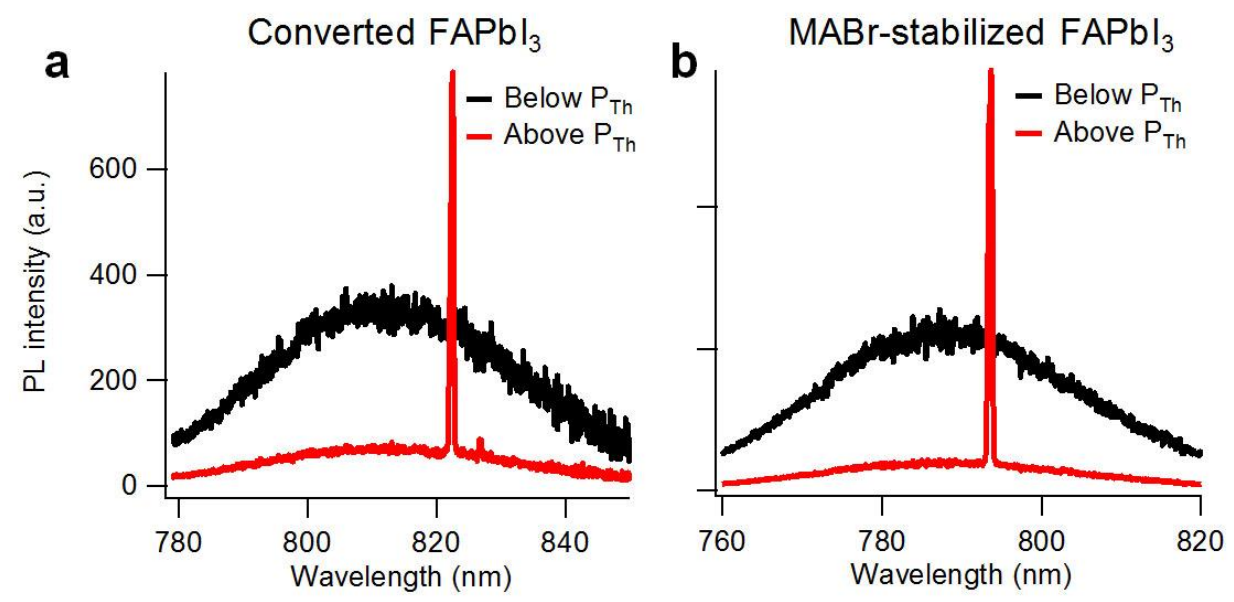

Figure S6. PL spectra with broader wavelength range below (black line) and above (red line) lasing threshold $\left(P_{\mathrm{Th}}\right)$ for representative (a) converted perovskite phase $\mathrm{FAPbI}_{3} \mathrm{NW}$, and (b) MABr-stabilized $\mathrm{FAPbI}_{3} \mathrm{NW}$. 


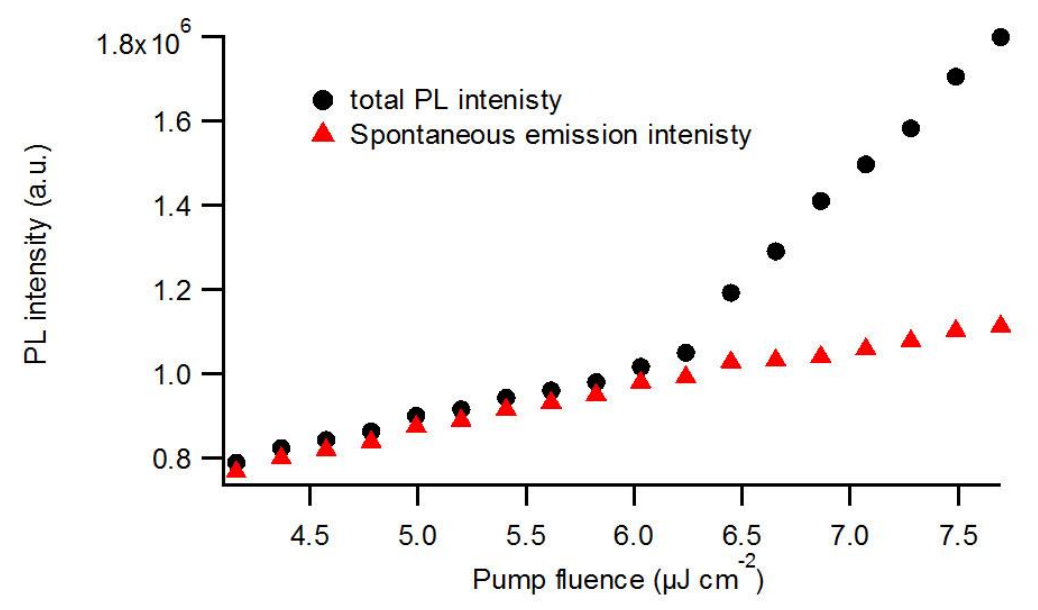

Figure S7. Total emission intensity and spontaneous emission intensity of the converted $\mathrm{FAPbI}_{3}$ NW as a function of pump fluence, showing the saturation of spontaneous emission after lasing occurrence.
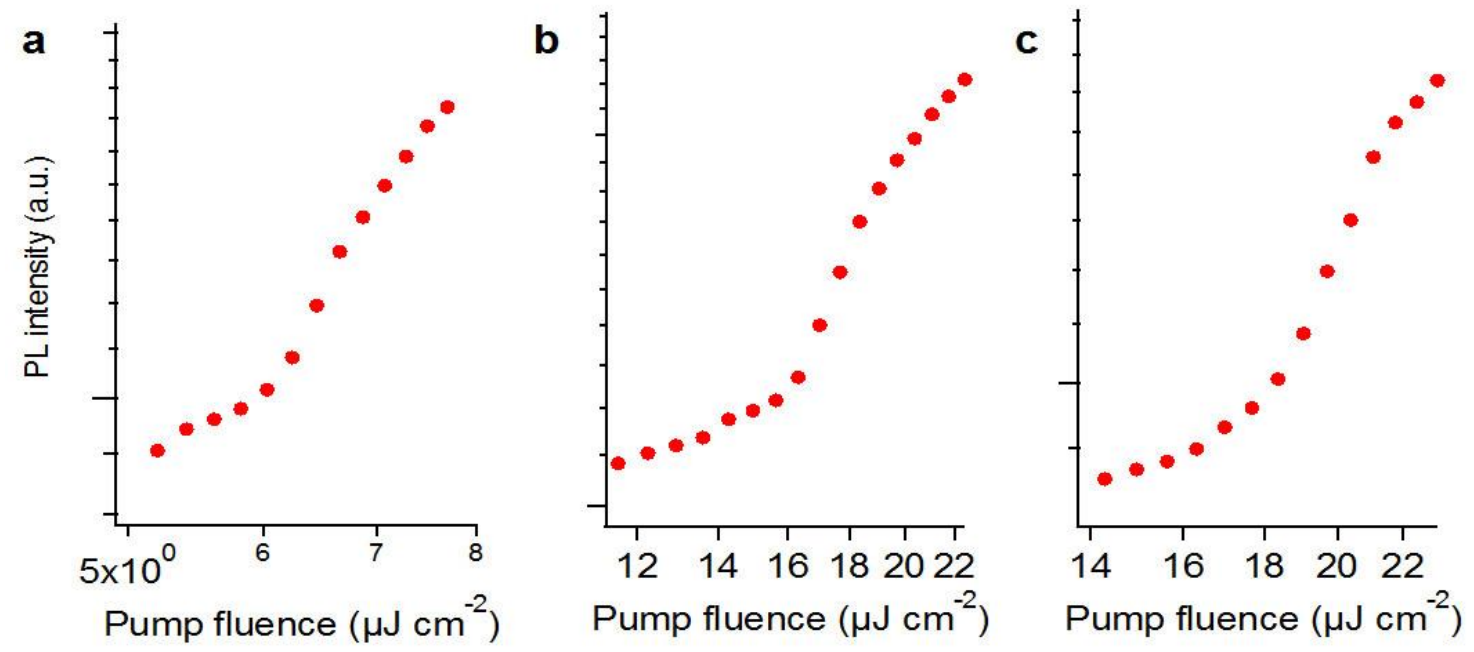

Figure S8. Log-log plots of the integrated PL intensity as a function of pump fluence for (a) the $\mathrm{FAPbI}_{3} \mathrm{NW}$ in Figure 2, and (b, c) a few additional $\mathrm{FAPbI}_{3} \mathrm{NW}$ lasers, showing the expected $\mathrm{S}$ shaped behavior for stimulated emission. 

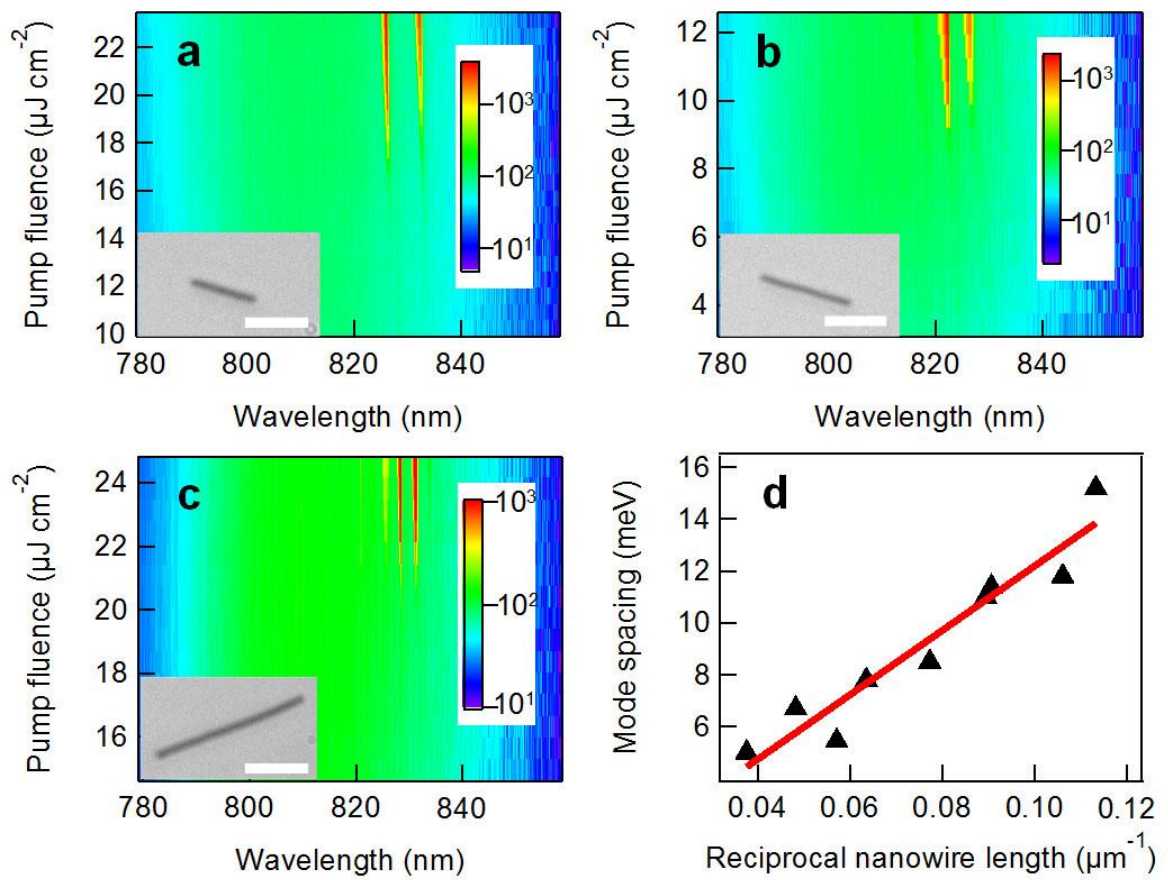

Figure S9. (a-c) 2D pseudo-color plots of the emission spectra of converted $\mathrm{FAPbI}_{3} \mathrm{NWs}$ with different lengths: (a) $11 \mu \mathrm{m}$, (b) $16 \mu \mathrm{m}$, (c) $27 \mu \mathrm{m}$. The scale bar is $10 \mu \mathrm{m}$. (d) Mode spacing of the lasing peaks as a function of reciprocal NW length (black triangles). The experimental data are well fitted by a linear function (red) with intercept at zero.
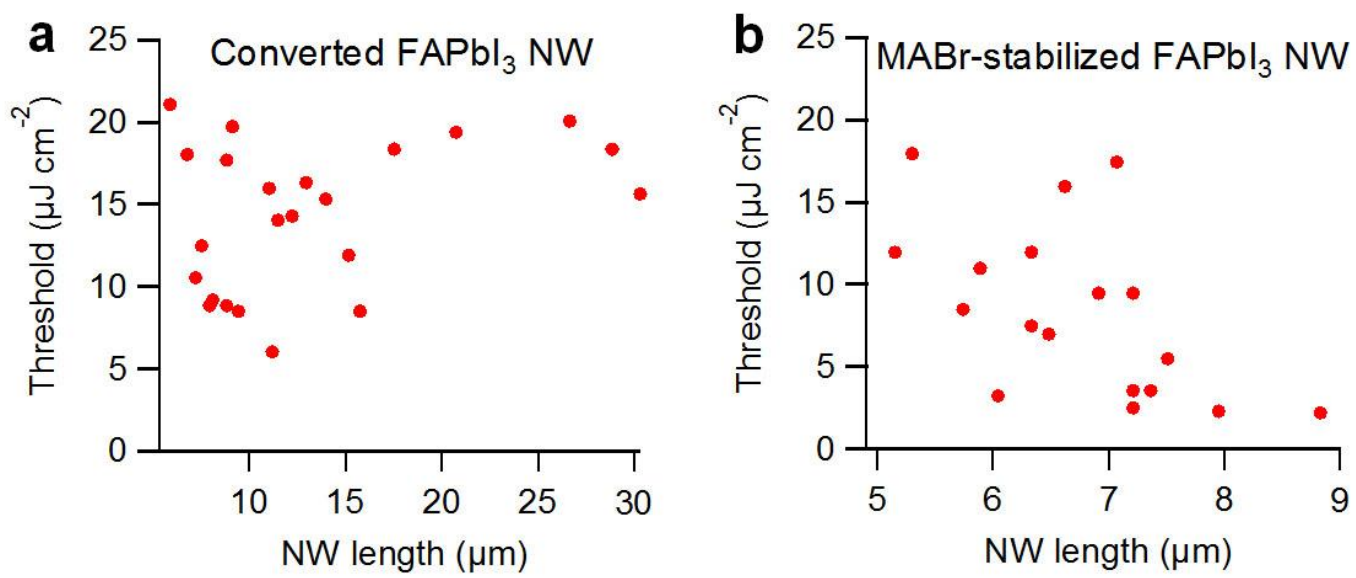

Figure S10. The lasing thresholds of a variety of (a) converted $\mathrm{FAPbI}_{3} \mathrm{NWs}$, and (b) $\mathrm{MABr}-$ stabilized $\mathrm{FAPbI}_{3} \mathrm{NWs}$ with different lengths. 


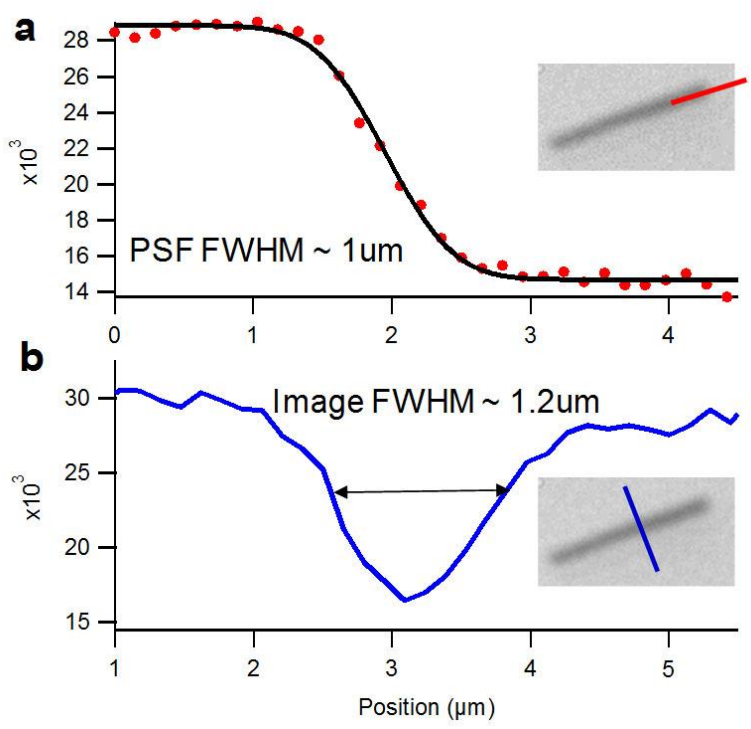

Figure S11. Illustration of the process to estimate the NW width. (a) Line intensity profile along NW axial direction and its fitting to an error function (a Gaussian function convoluted with a step function), which gives the full-width-at-half-maximum (FWHM) of point-spread-function (PSF) about $1 \mu \mathrm{m}$. (b) Line intensity profile perpendicular to NW direction with a FWHM of $1.2 \mu \mathrm{m}$. Simple deconvolution yields an estimated width of $0.7 \mu \mathrm{m}$ for this NW.

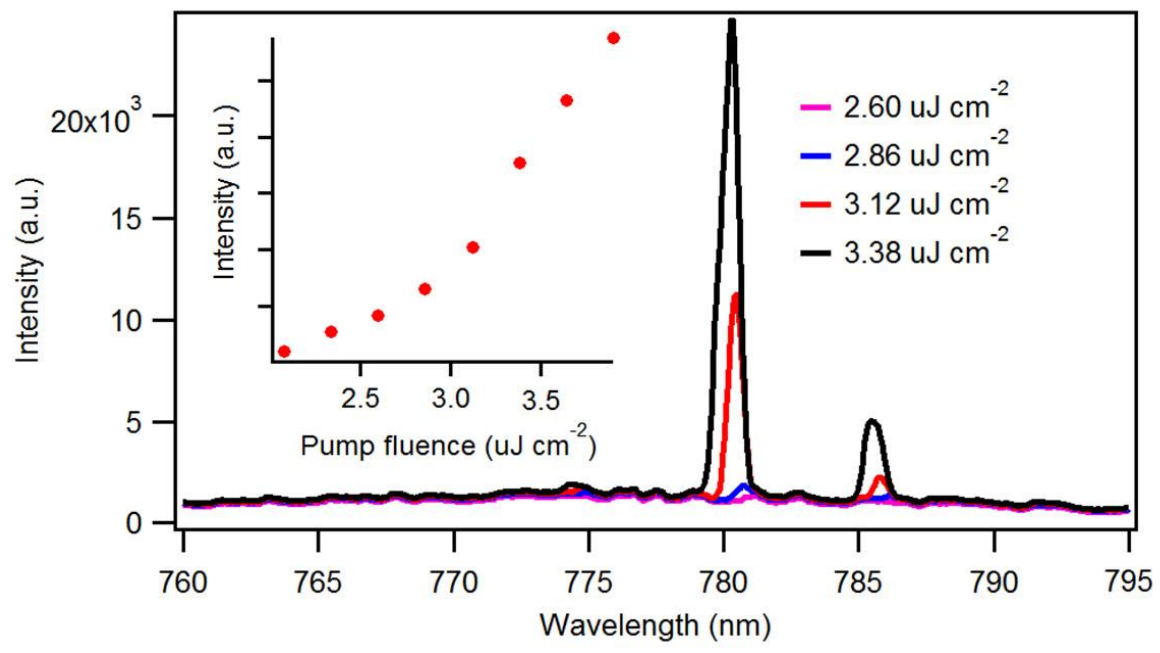

Figure $\mathrm{S} 12 . \mathrm{MAPbI}_{3} \mathrm{NW}$ emission spectra around the lasing threshold. Inset: Integrated emission intensity as a function of $P$ showing the lasing threshold of $\sim 3 \mu \mathrm{J} \mathrm{cm}{ }^{-2}$ 


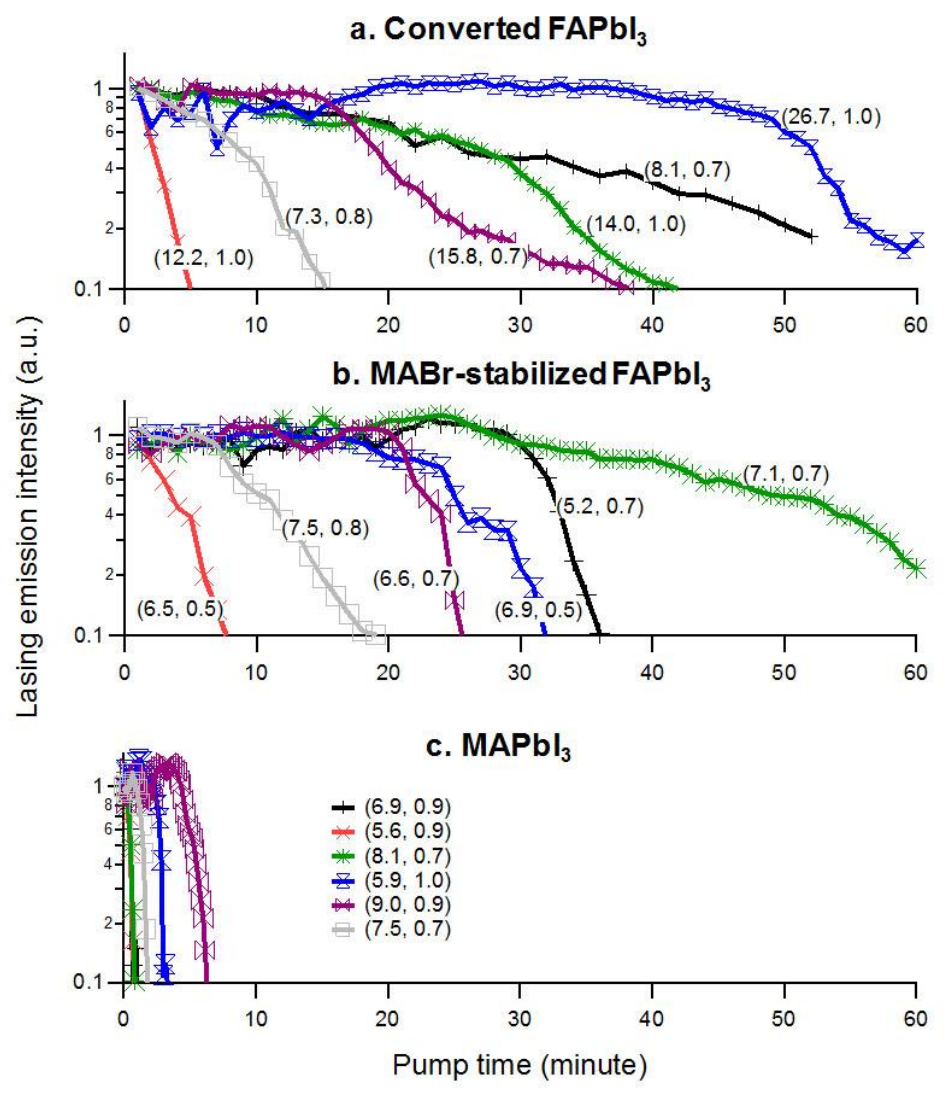

Figure S13. Lasing emission intensity of additional representative perovskite NWs with various length and width of (a) converted perovskite $\mathrm{FAPbI}_{3}$, (b) $\mathrm{MABr}$-stabilized $\mathrm{FAPbI}_{3}$, and (c) $\mathrm{MAPbI}_{3}$, as a function of the pump time with up to $\sim 1 \mathrm{~h}$ of continuous illumination of $402 \mathrm{~nm}$ pulsed laser excitation $(150 \mathrm{fs}, 250 \mathrm{kHz})$ at room temperature. The numbers in brackets $(\mathrm{L}, \mathrm{W})$ denoted the NW length and estimated width in micrometers based on the optical images. There is no clear dependence of lasing stability on the NW dimensions, but both converted perovskite $\mathrm{FAPbI}_{3}$ and $\mathrm{MABr}$-stabilizied $\mathrm{FAPbI}_{3} \mathrm{NWs}$ show much improved photostability compared to $\mathrm{MAPbI}_{3} \mathrm{NWs}$ that is statistically significant. 

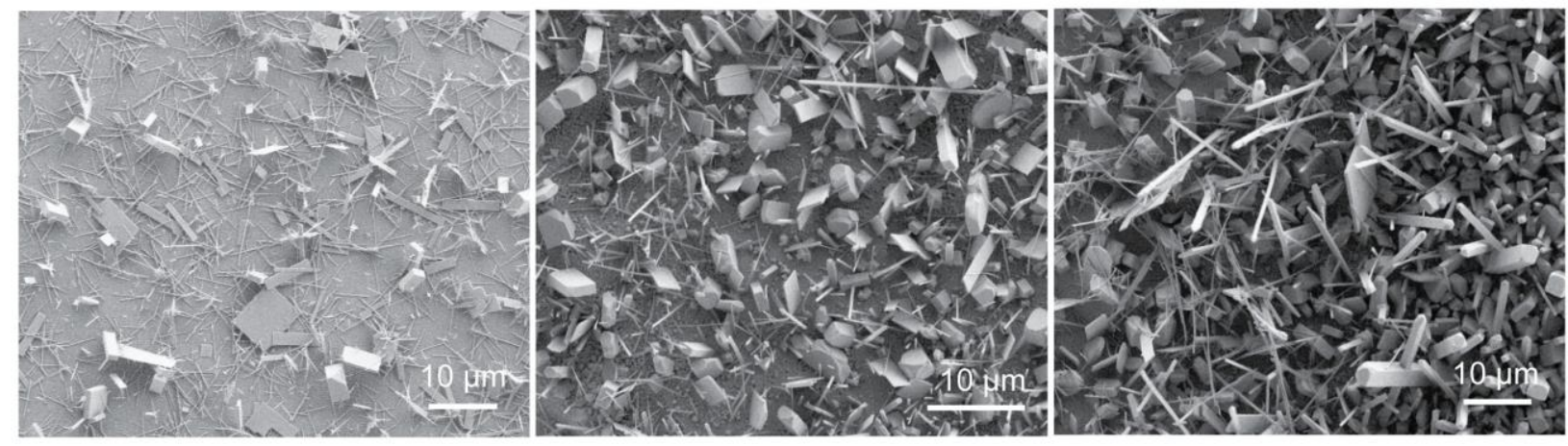

Figure S14. Additional SEM images of as-grown $\mathrm{FAPbBr}_{3} \mathrm{NWs}$.

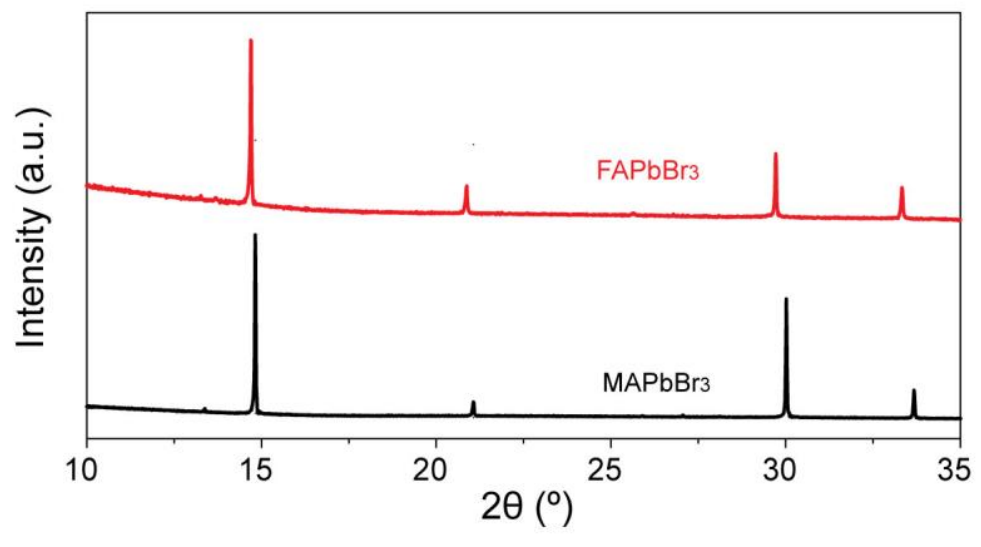

Figure S15. PXRD patterns of as-grown $\mathrm{FAPbBr}_{3} \mathrm{NWs}$ and $\mathrm{MAPbBr}_{3} \mathrm{NWs}$. 

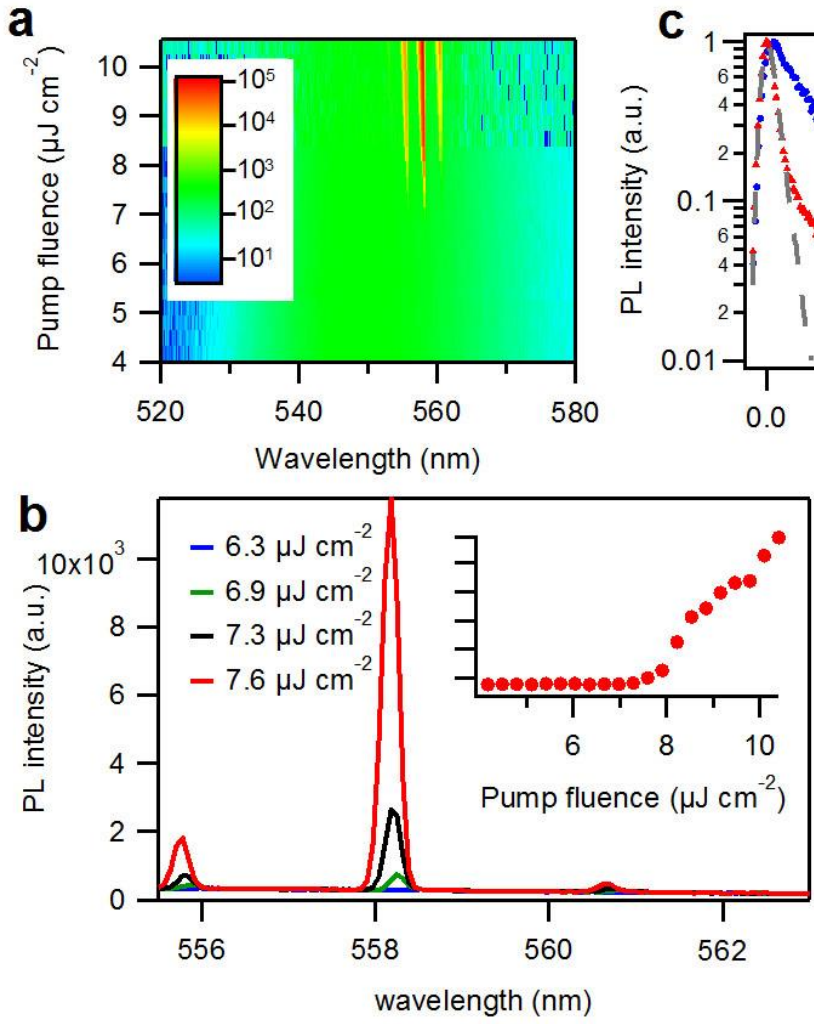

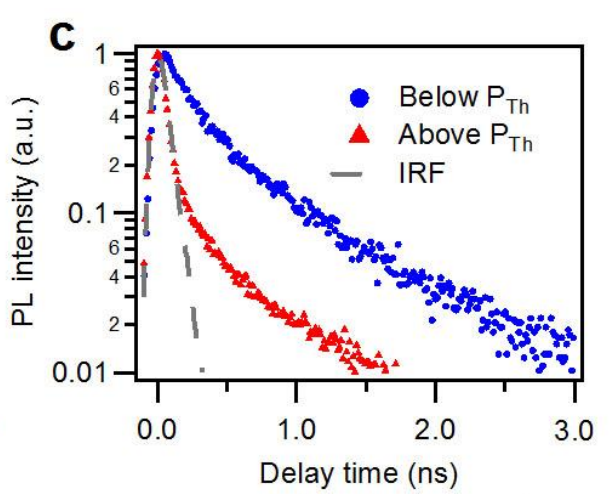

d

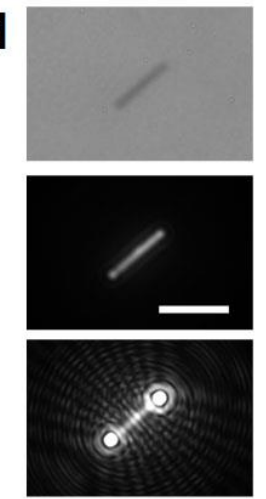

Figure S16. Visible lasing from $\mathrm{FAPbBr}_{3}$ NWs. (a) 2D pseudo-color plot of the emission spectra under different pump fluences $(P)$. Note the intensity is in logarithm scale. (b) NW emission spectra around the lasing threshold. Inset: Integrated emission intensity as a function of $P$ showing the lasing threshold $\sim 7 \mu \mathrm{J} \mathrm{cm}^{-2}$. (c) Time-resolved PL decay kinetics of NW below (blue circles) and above (red triangles) lasing threshold. (d) Optical image (upper panel) and fluorescence images of a single NW below (middle panel) and above (lower panel) lasing threshold. 

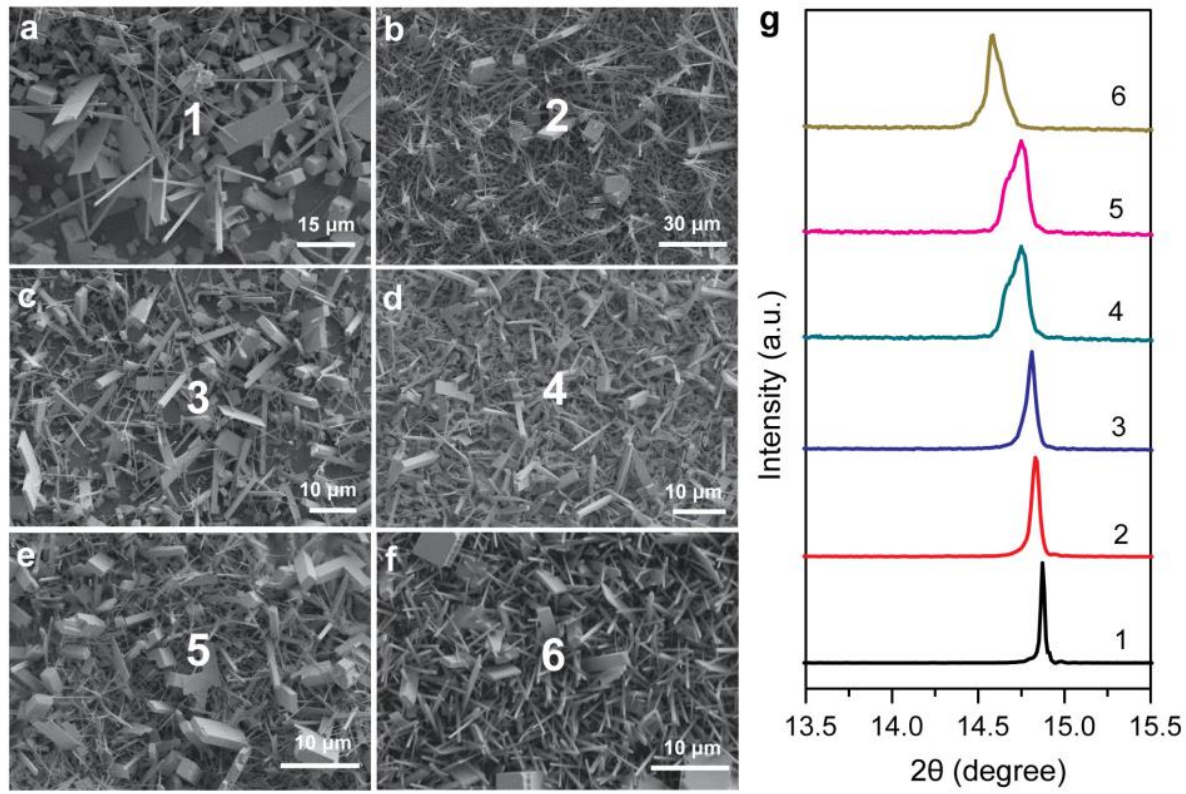

Figure S17. Structural characterizations of $\mathrm{NWs}$ of $\mathrm{MAPb}(\mathrm{Br}, \mathrm{I})_{3}$ alloys. SEM images of the $\operatorname{MAPb}(\mathrm{Br}, \mathrm{I})_{3}$ alloy NWs grown using a mixed IPA solution of (a) $7 \mathrm{mg} / \mathrm{mL} \mathrm{MABr}$, (b) $7 \mathrm{mg} / \mathrm{mL}$ MABr and $1 \mathrm{mg} / \mathrm{mL}$ MAI, (c) $7 \mathrm{mg} / \mathrm{mL}$ MABr and $2 \mathrm{mg} / \mathrm{mL}$ MAI, (d) $7 \mathrm{mg} / \mathrm{mL}$ MABr and 3 $\mathrm{mg} / \mathrm{mL}$ MAI, (e) $7 \mathrm{mg} / \mathrm{mL} \mathrm{MABr}$ and $4 \mathrm{mg} / \mathrm{mL}$ MAI, (f) $7 \mathrm{mg} / \mathrm{mL}$ MABr and $5 \mathrm{mg} / \mathrm{mL}$ MAI. These NWs are labeled as 1-6, respectively. (g) The corresponding PXRD patterns show the (001) diffraction peak gradually shifts to smaller angle, confirming the increase of iodide percentage in the $\operatorname{MAPb}(\mathrm{Br}, \mathrm{I})_{3}$ alloys. 

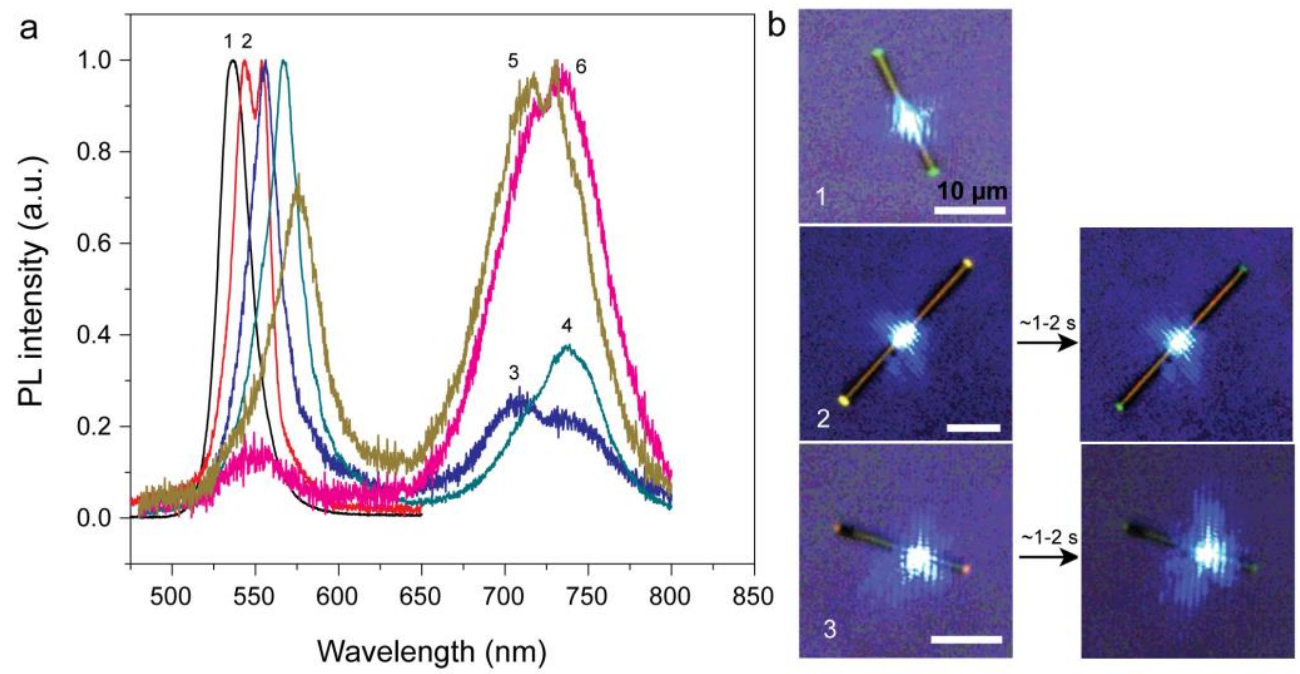

Figure S18. (a) Confocal microscopy photoluminescence spectra of individual $\mathrm{MAPb}(\mathrm{Br}, \mathrm{I})_{3}$ NWs excited by a $442 \mathrm{~nm}$ laser source at room temperature. Interestingly, the PL peaks do not show continuous shift with increasing iodide content in the $\mathrm{MAPb}(\mathrm{Br}, \mathrm{I})_{3}$ alloy NWs. Specifically, the NWs 3-6 (note, the labels of these NWs are the same as the ones labeled in Figure S9) that could not lase at room temperature often display two PL peaks located at $\sim 560 \mathrm{~nm}$ and $\sim 730 \mathrm{~nm}$. One of the peaks will gradually increase in intensity upon prolonged or intense illumination, while the other peak will decrease and eventually disappear. The results are basically in agreement with the previous report, ${ }^{\mathrm{S} 3}$ except that it is irreversible. We speculate that these NWs are prone to decomposition under intense laser illumination. Due to the photo-instability of these NWs in composition range of these $\mathrm{MAPb}(\mathrm{Br}, \mathrm{I})_{3}$ perovskites, lasing could not be achieved in the spectra region from $580 \mathrm{~nm}$ to $650 \mathrm{~nm}$ with just MA perovskites. (b) Optical images of NWs 1-3 excited by a $442 \mathrm{~nm}$ laser, showing strong waveguiding effect along the axial direction. However, the emissions are not stable upon intense illumination as shown by the color change of the light emitted from the ends of NWs. 

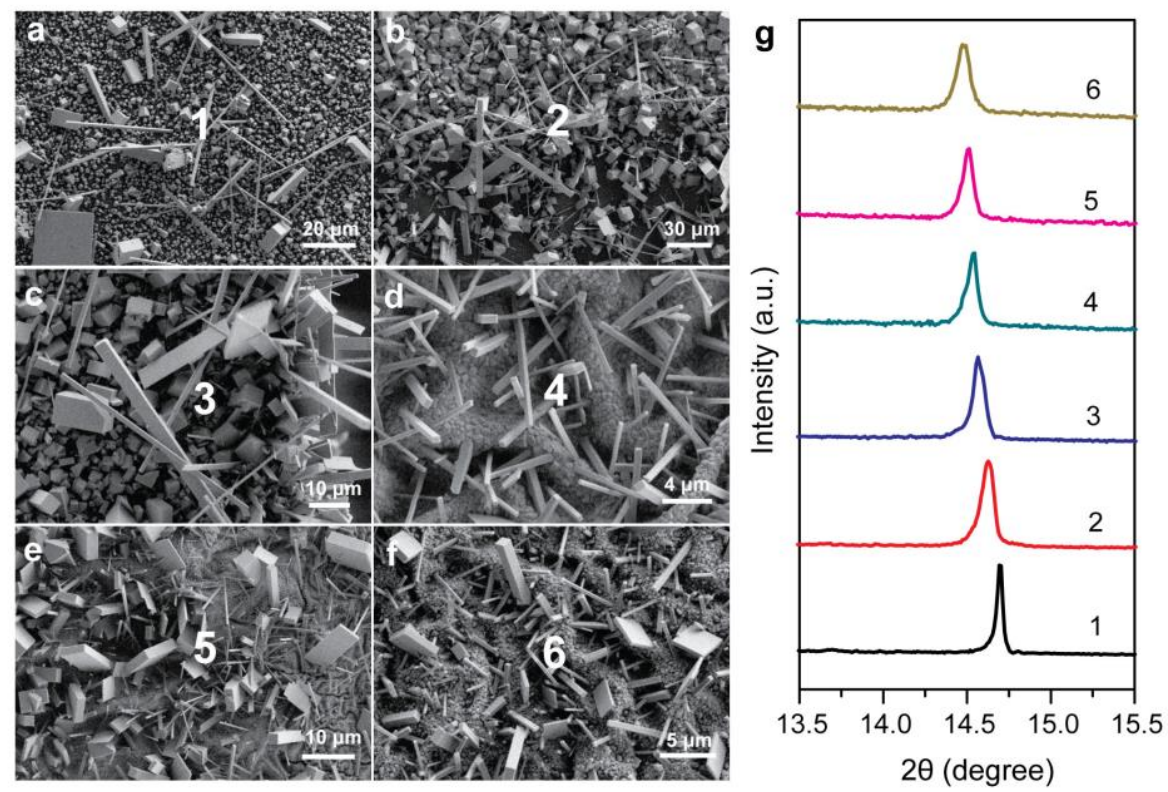

Figure S19. Structural characterizations of (FA,MA) $\mathrm{Pb}(\mathrm{Br}, \mathrm{I})_{3}$ alloy NWs. SEM images of the (FA,MA) $\mathrm{Pb}(\mathrm{Br}, \mathrm{I})_{3}$ alloy NWs grown using a mixed IPA solution of (a) $10 \mathrm{mg} / \mathrm{mL} \mathrm{FABr}$, (b) 7 $\mathrm{mg} / \mathrm{mL} \mathrm{FABr}$ and $1 \mathrm{mg} / \mathrm{mL}$ MAI, (c) $7 \mathrm{mg} / \mathrm{mL}$ FABr and $2 \mathrm{mg} / \mathrm{mL}$ MAI, (d) $7 \mathrm{mg} / \mathrm{mL} \mathrm{FABr}$ and $3 \mathrm{mg} / \mathrm{mL}$ MAI, (e) $7 \mathrm{mg} / \mathrm{mL} \mathrm{FABr}$ and $4 \mathrm{mg} / \mathrm{mL}$ MAI, (f) $7 \mathrm{mg} / \mathrm{mL} \mathrm{FABr}$ and $5 \mathrm{mg} / \mathrm{mL}$ MAI. These NWs are labeled as 1-6, respectively. (g) The corresponding PXRD patterns showing the shift of the (001) diffraction peak. The stoichiometry of alloy NWs 2-6 were determined by EDS and ${ }^{1} \mathrm{H}$ NMR measurements to be $\left(\mathrm{FA}_{0.79} \mathrm{MA}_{0.21}\right) \mathrm{Pb}\left(\mathrm{Br}_{2.87} \mathrm{I}_{0.13}\right)$, $\left(\mathrm{FA}_{0.71} \mathrm{MA}_{0.29}\right) \mathrm{Pb}\left(\mathrm{Br}_{2.78} \mathrm{I}_{0.22}\right), \quad\left(\mathrm{FA}_{0.67} \mathrm{MA}_{0.33}\right) \mathrm{Pb}\left(\mathrm{Br}_{2.69} \mathrm{I}_{0.31}\right), \quad\left(\mathrm{FA}_{0.57} \mathrm{MA}_{0.43}\right) \mathrm{Pb}\left(\mathrm{Br}_{2.63} \mathrm{I}_{0.37}\right)$ and $\left(\mathrm{FA}_{0.54} \mathrm{MA}_{0.46}\right) \mathrm{Pb}\left(\mathrm{Br}_{2.45} \mathrm{I}_{0.55}\right)$, respectively. 

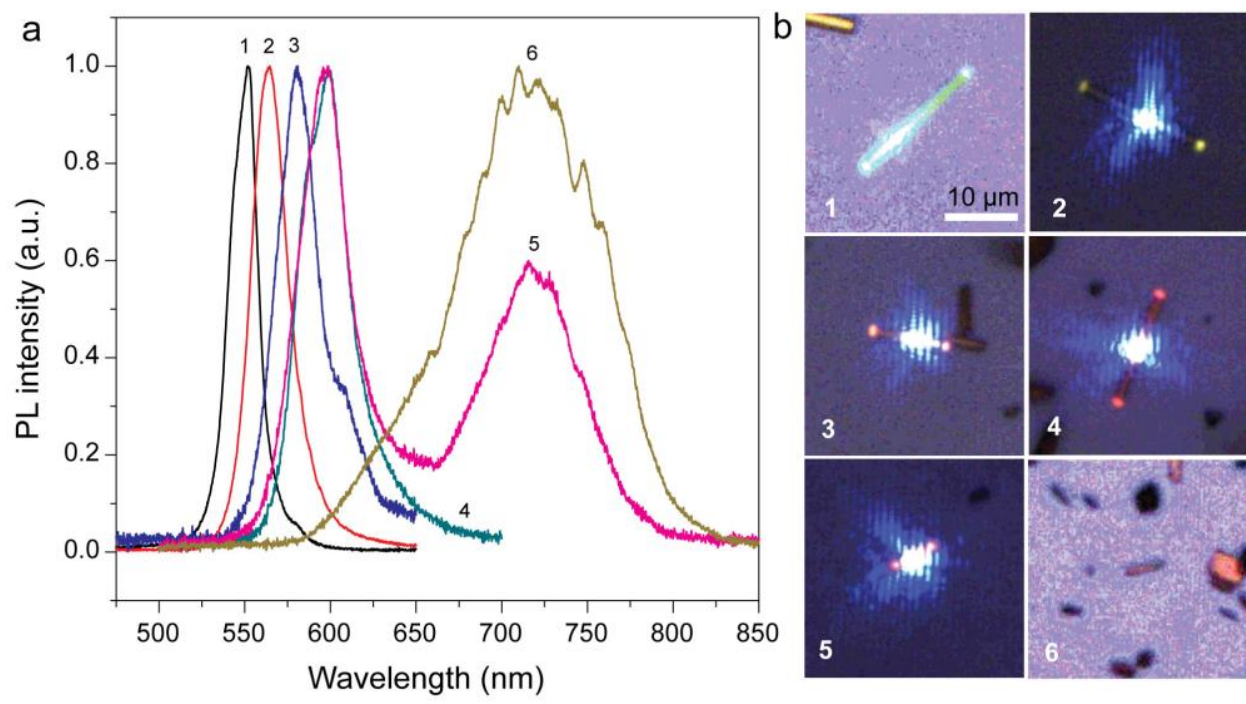

Figure S20. (a) Confocal microscopy photoluminescence of individual (FA,MA) $\mathrm{Pb}(\mathrm{Br}, \mathrm{I})_{3} \mathrm{NWs}$ excited by a $442 \mathrm{~nm}$ laser source at room temperature. The PL peak continuously blue-shifts until $\sim 620 \mathrm{~nm}$ upon increasing the MAI content from NW 1 to NW 4 (the labels of these NWs are the same as the ones labeled in Figure S11), reflecting the increasing optical band gaps in such alloyed NWs. However, when the MAI content is further increased in the NW 5 and $\mathbf{6}$, the PL spectra show two emission peaks at $\sim 620 \mathrm{~nm}$ and $\sim 720 \mathrm{~nm}$ or single emission at $\sim 720 \mathrm{~nm}$ and these NWs do not lase at room temperature. (b) Optical images of NWs 1-5 excited by a 442 nm laser and NW 6, showing strong waveguiding effect along the axial direction. The emissions are much more robust compared to the $\mathrm{MAPb}(\mathrm{Br}, \mathrm{I})_{3} \mathrm{NWs}$ at the same illuminating density that are shown in Figure S10. 

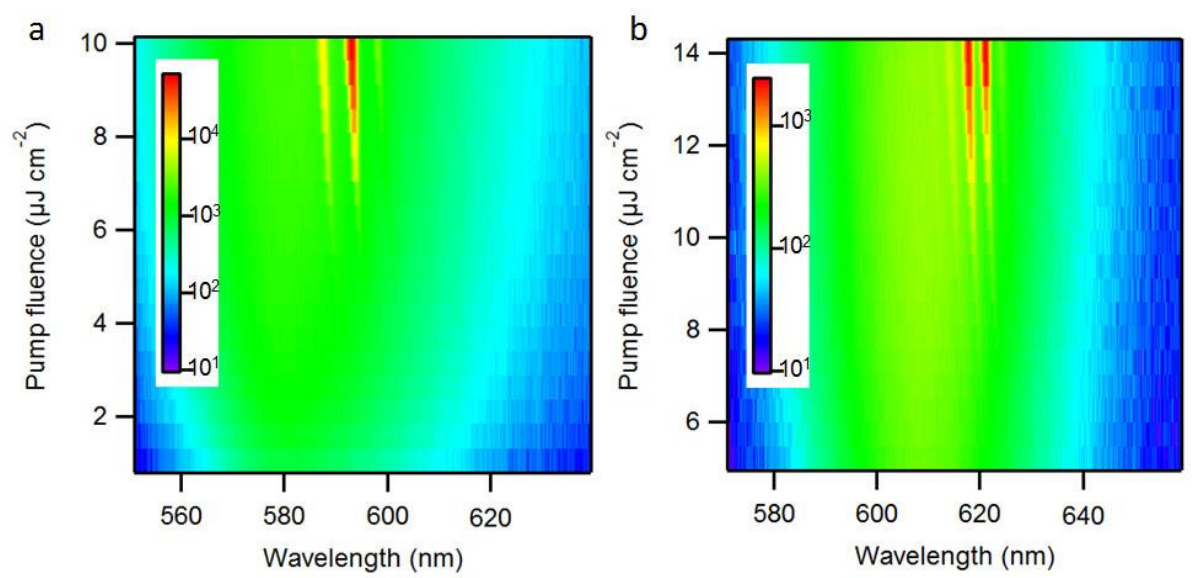

Figure S21. 2D pseudo-color plots of the emission spectra of $\left(\mathrm{FA}_{0.71} \mathrm{MA}_{0.29}\right) \mathrm{Pb}\left(\mathrm{Br}_{2.78} \mathrm{I}_{0.22}\right)$ and $\left(\mathrm{FA}_{0.67} \mathrm{MA}_{0.33}\right) \mathrm{Pb}\left(\mathrm{Br}_{2.69} \mathrm{I}_{0.31}\right)$ alloy $\mathrm{NWs}$ under different pump fluences, showing the new lasing wavelength at $595 \mathrm{~nm}$ and $621 \mathrm{~nm}$, respectively. These lasing wavelengths could not be achieved with just MA-based perovskite NWs.
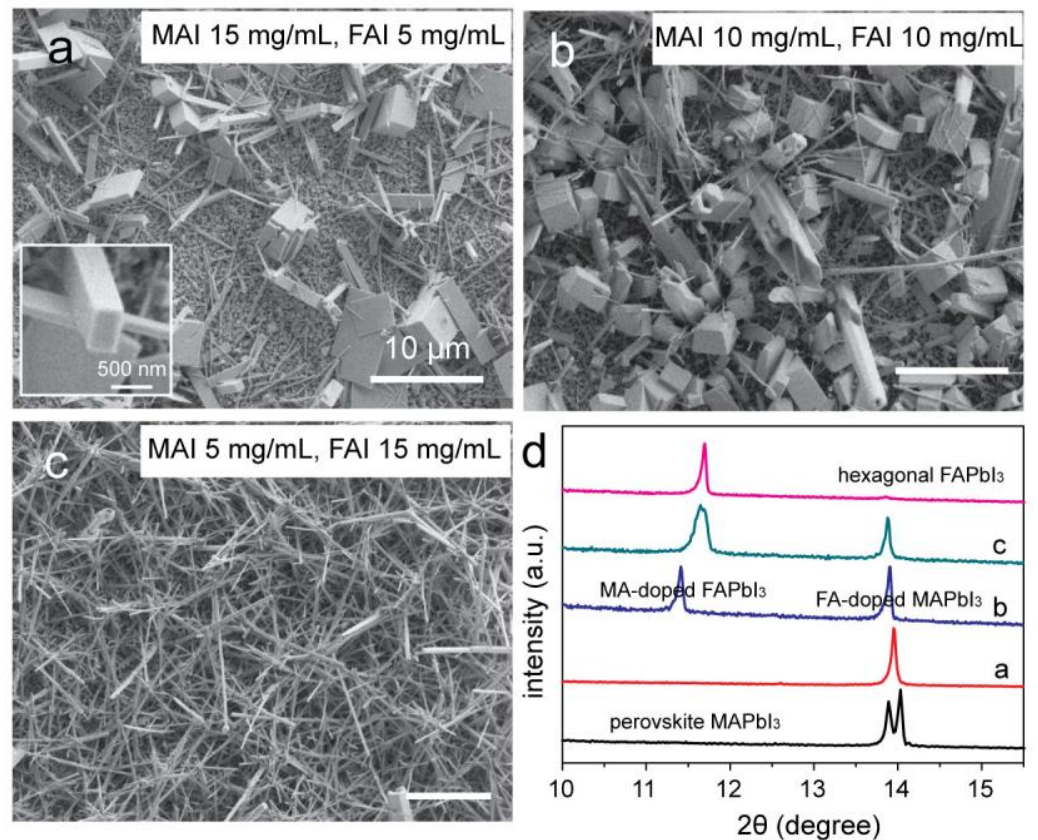

Figure S22. Structural characterizations of (FA,MA)PbI 3 alloy NWs. SEM images of the (FA,MA)PbI ${ }_{3}$ alloy $\mathrm{NWs}$ grown using a mixed IPA solution of (a) $15 \mathrm{mg} / \mathrm{mL}$ MAI and $5 \mathrm{mg} / \mathrm{mL}$ FAI, (b) $10 \mathrm{mg} / \mathrm{mL}$ MAI and $10 \mathrm{mg} / \mathrm{mL}$ FAI, (c) $5 \mathrm{mg} / \mathrm{mL}$ MAI and $15 \mathrm{mg} / \mathrm{mL}$ FAI. The alloys are labeled as A, B and $\mathbf{C}$, respectively. (d) The corresponding PXRD patterns show the shift of 
the (001) diffraction peak of the pseudo-cubic phase, confirming the alloying of FA and MA cations. In additional, the (FA, $\mathrm{MA}) \mathrm{PbI}_{3}$ alloy $\mathbf{A}$ exhibits only a stabilized perovskite phase, while alloys $\mathbf{B}$ and $\mathbf{C}$ exhibit both stabilized perovskite phase and hexagonal phase. The results suggest MA can help to stabilize the perovskite phase of $\mathrm{FAPbI}_{3}$ and induce the cubic perovskite structure, in agreement with previous study. ${ }^{\mathrm{S}} 4$

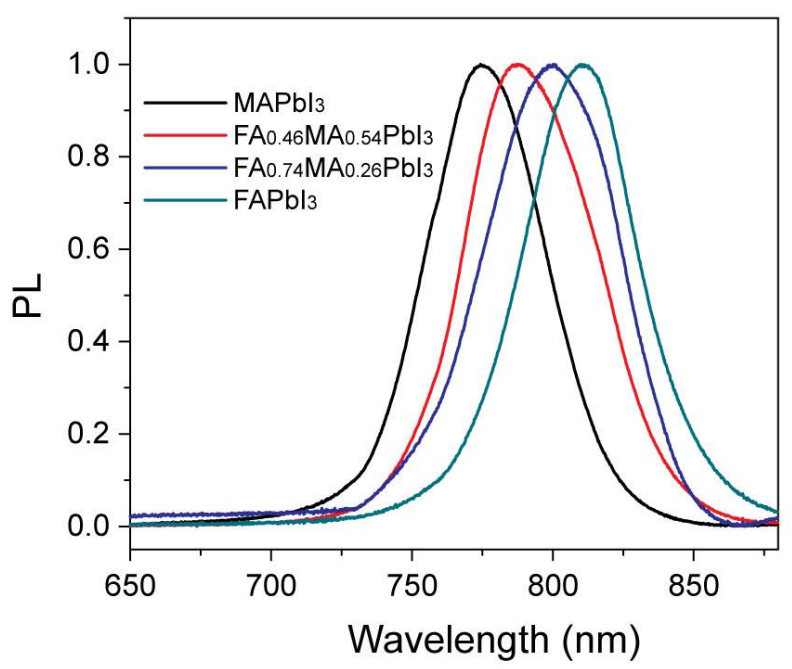

Figure S23. Photoluminescence spectra of (FA,MA) $\mathrm{PbI}_{3}$ alloys $\mathbf{A}$ and $\mathbf{B}$. For comparison, the photoluminescence spectra of $\mathrm{MAPbI}_{3}$ and $\mathrm{FAPbI}_{3}$ perovskites are also provided. The stoichiometry of alloys $\mathbf{A}$ and $\mathbf{B}$ are further determined to be $\left(\mathrm{FA}_{0.46} \mathrm{MA}_{0.54}\right) \mathrm{PbI}_{3}$ and $\left(\mathrm{FA}_{0.74} \mathrm{MA}_{0.26}\right) \mathrm{PbI}_{3}$, respectively, by the shift of PL peak. 


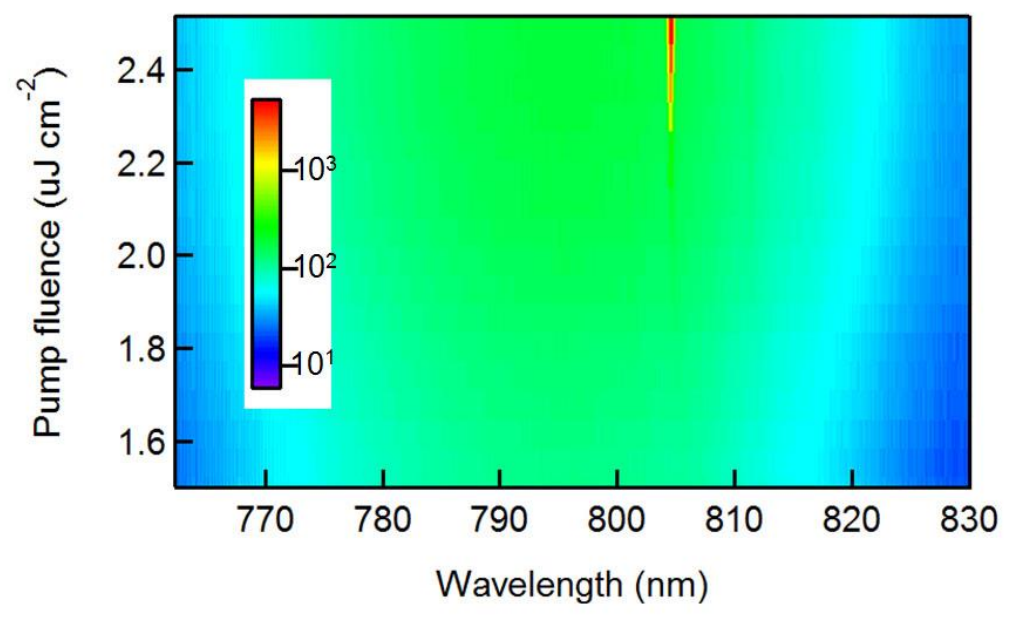

Figure S24. 2D pseudo-color plot of the emission spectra of a $\left(\mathrm{FA}_{0.46} \mathrm{MA}_{0.54}\right) \mathrm{PbI}_{3} \mathrm{NW}$ under different pump fluences, showing the lasing wavelength at $805 \mathrm{~nm}$.

\section{References}

S1. Eperon, G. E.; Stranks, S. D.; Menelaou, C.; Johnston, M. B.; Herz, L. M.; Snaith, H. J. Energy Environ. Sci. 2014, 7, 982-988.

S2. $\quad$ Zhu, H.; Fu, Y.; Meng, F.; Wu, X.; Gong, Z.; Ding, Q.; Gustafsson, M. V.; Trinh, M. T.; Jin, S.; Zhu, X. Nat. Mater. 2015, 14, 636-642.

S3. Hoke, E. T.; Slotcavage, D. J.; Dohner, E. R.; Bowring, A. R.; Karunadasa, H. I.; McGehee, M. D. Chem. Sci. 2015, 6, 613-617.

S4. $\quad$ Binek, A.; Hanusch, F. C.; Docampo, P.; Bein, T. J. Phys. Chem. Lett. 2015, 6, 1249-1253. 